\title{
INTERFACE EDUCAÇÃO ESPECIAL - EDUCAÇÃO DO CAMPO: DIRETRIZES POLÍTICAS E PRODUÇÃO DO CONHECIMENTO NO BRASIL
}

\author{
Washington Cesar Shoiti NOZU ${ }^{1}$ \\ Marilda Moraes Garcia BRUNO ${ }^{2}$ \\ Eladio SEBASTIÁN HEREDERO ${ }^{3}$
}

Resumo: Este texto tem como foco o estudo da articulação entre a educação especial e a educação do campo. Mais precisamente, busca apresentar o cenário político e epistemológico da interface entre essas modalidades de educação no Brasil. Para tanto, as ideias elucidadas no trabalho foram organizadas em três momentos. Inicialmente, foram selecionados dispositivos relativos à educação especial, à educação do campo e à interface entre ambas, previstos nos documentos político-normativos brasileiros. $\mathrm{Na}$ sequência, aponta um breve panorama da produção de conhecimento acadêmico, registrando teses e dissertações e a atuação de alguns grupos de pesquisa que discutem a temática. Por fim, estabelece aproximações entre a educação especial e a educação do campo e acena para alguns desafios políticos e epistemológicos para a interface entre essas modalidades educacionais.

Palavras-chave: Educação inclusiva. Educação especial. Educação do campo.

\section{INTRODUÇÃO}

O princípio da educação inclusiva, amplamente divulgado em declarações internacionais a partir da década de 1990, tem defendido o direito fundamental à educação de todas as pessoas, independentemente de suas condições físicas, sensoriais, intelectuais, sociais, étnicas, culturais, etárias, linguísticas, religiosas e de gênero.

Neste sentido, a Declaração de Salamanca (UNESCO, 1994) - documento considerado como a certidão de nascimento da proposta da educação inclusiva - indica que a escola, constituindo-se num espaço heterogêneo, deve criar estratégias para satisfazer a diversidade de necessidades, características, interesses, habilidades e potencialidades dos alunos.

De acordo com Sebastián Heredero (2010, p.197),

\footnotetext{
1 UFGD - Universidade Federal da Grande Dourados. Programa de Pós-Graduação em Educação. Dourados - MS - Brasil. 79825-070 - wcsn1984@yahoo.com.br.

${ }^{2}$ UFGD - Universidade Federal da Grande Dourados. Programa de Pós-Graduação em Educação. Dourados - MS - Brasil.79825-070 - marildabruno@ufgd.edu.br.

${ }^{3}$ UAH - Universidad de Alcalá. Departamento de Didática. Guadalajara - Castilla La Mancha - Espanha. 19001 - eladio.sebastian@gmail.com.
} 
O movimento pela inclusão constitui numa postura ativa de identificação das barreiras que alguns grupos encontram no acesso à educação, e também na busca dos recursos necessários para ultrapassá-las, consolidando um novo paradigma educacional de construção de uma escola aberta às diferenças.

Cumpre salientar que, embora todos os estudantes sejam virtualmente considerados sujeitos de uma educação inclusiva, a materialidade mostra que algumas populações têm sido historicamente alijadas do gozo ao direito à educação e de outros direitos sociais (saúde, trabalho, lazer, alimentação, moradia, entre outros). Dentre estas populações, destacam-se, neste estudo, aquelas que vivem no campo e as que se encontram em situação de deficiência.

Em face desta realidade, já que a educação inclusiva “[...] refere-se a um objetivo político a ser alcançado" (BUENO, 2008, p.49), é preciso que o poder público garanta, fundamentado em razões plausíveis, "políticas de diferença” (HALL, 2011) para efetivar o direito à educação destas populações marginalizadas, deslocadas e estigmatizadas.

No caso das pessoas em condição de deficiência e das pessoas que vivem no campo, a garantia do direito social à educação tem se configurado, no Brasil, até certa medida, como atuação tímida, descentrada e ambivalente de ambas as modalidades de educação: a especial e a do campo.

Entretanto, o histórico brasileiro para com estas duas áreas educacionais é de descaso (CAIADO, 2015): de um lado, a educação especial constituiu-se como um “apêndice indesejável” da educação comum (MAZZOTTA, 2005); por outro lado, a educação do campo é considerada um "resíduo" do sistema educacional urbano (FERNANDES; CERIOLI; CALDART, 2011).

Dessa maneira, se trabalhar com estas duas modalidades educacionais, de forma isolada, já denota atividade árdua, face as suas peculiaridades e complexidades, disporse a trabalhar na interface dessas duas áreas significa adentrar numa arena de grandes desafios (CAIADO; MELETTI, 2011). Desafios que têm sido recentemente assumidos, ainda que timidamente, pelas pesquisas e pelas políticas educacionais brasileiras.

Neste contexto, com vistas a refletir acerca das possibilidades diante daquilo que ainda não é, mas que poderá vir a ser (SANTOS, 2007), o presente trabalho busca apresentar, nos limites de um artigo, o cenário político e epistemológico da interface entre a educação especial e a educação do campo no Brasil. Para tanto, inicialmente, o texto seleciona nos documentos político-normativos os dispositivos relativos à educação 
especial e à educação do campo, bem como aqueles que tratam da interface entre estas duas modalidades educacionais. Na sequência, delineia um breve panorama da produção de conhecimento acadêmico que trata desta interface. Por fim, estabelece aproximações entre a educação especial e a educação do campo a acena para alguns desafios políticos e epistemológicos.

\section{O cenário político: as diretrizes brasileiras para a interface educação especial - educação do campo}

A Política Nacional de Educação Especial na Perspectiva da Educação Inclusiva (BRASIL, 2008a) conceitua a educação especial como “[...] modalidade de ensino que perpassa todos os níveis, etapas e modalidades, realiza o atendimento educacional especializado, disponibiliza os recursos e serviços e orienta quanto a sua utilização no processo de ensino e aprendizagem nas turmas comuns do ensino regular" (grifo nosso). Os sujeitos considerados público-alvo da educação especial compreendem alunos com deficiências, transtornos globais do desenvolvimento e altas habilidades/superdotação (BRASIL, 2008a).

Diante desta perspectiva, a educação especial tem voltado sua atuação para a realização do atendimento educacional especializado, “[...] compreendido como o conjunto de atividades, recursos de acessibilidade e pedagógicos organizados institucional e continuamente [...]" (BRASIL 2011). O atendimento educacional especializado tem “[...] como função identificar, elaborar e organizar recursos pedagógicos e de acessibilidade que eliminem as barreiras para a plena participação dos alunos, considerando suas necessidades específicas". (BRASIL, 2008a).

$\mathrm{O}$ atendimento educacional especializado deve ser ofertado no turno inverso ao da escolarização, na própria escola comum, em outra escola de ensino regular ou em centro especializado que realize tal serviço (BRASIL, 2009). Ademais, os dispositivos recomendam que este atendimento não tenha caráter substitutivo às classes comuns (BRASIL, 2008a; 2009), buscando complementar a formação dos estudantes com deficiência e transtornos globais do desenvolvimento e suplementar a formação dos alunos com altas habilidades/superdotação (BRASIL, 2011).

As Diretrizes Operacionais para o Atendimento Educacional Especializado na Educação Básica (BRASIL, 2009) dispõem que este serviço seja ofertado prioritariamente nas salas de recursos multifuncionais - definidas como “[...] ambientes 
dotados de equipamentos, mobiliários e materiais didáticos e pedagógicos para a oferta do atendimento educacional especializado”. (BRASIL, 2011).

$\mathrm{Na}$ sequência, apresentar-se-á alguns elementos para a compreensão da educação do campo (grifo nosso). De logo, vale salientar que definição da educação do campo não é "fixa" nem "fechada num conjunto de palavras" (MUNARIM, 2011), mas está num movimento de construção teórica. Trata-se de uma concepção de educação que está sendo configurada "[...] a partir da luta pela terra e por políticas públicas empreendida pelos movimentos e organizações sociais do campo". (MUNARIM, 2011, p.10).

A Resolução CNE/CEB n. 2/2008, que estabelece diretrizes complementares, normas e princípios para o desenvolvimento de políticas públicas de atendimento da Educação Básica do Campo, dispõe, em seu Art. $1^{\circ}$, que:

\begin{abstract}
A Educação do Campo compreende a Educação Básica em suas etapas de Educação Infantil, Ensino Fundamental, Ensino Médio e Educação Profissional Técnica de nível médio integrada com o Ensino Médio e destina-se ao atendimento às populações rurais em suas mais variadas formas de produção da vida [...] (BRASIL, 2008b).
\end{abstract}

O mesmo artigo da referida Resolução considera como sujeitos da educação do campo as populações do campo, que compreendem “[...] agricultores familiares, extrativistas, pescadores artesanais, ribeirinhos, assentados e acampados da Reforma Agrária, quilombolas, caiçaras, indígenas e outros”. (BRASIL, 2008b).

Para a oferta da educação básica do campo, conforme o Art. 28 da Lei de Diretrizes e Bases da Educação Nacional, os sistemas de ensino deverão atentar-se às peculiaridades da vida no campo e prever: conteúdos curriculares e metodologias apropriadas às necessidades e interesses dos alunos do campo; organização escolar própria, incluindo adequação do calendário escolar às fases do ciclo agrícola e às condições climáticas; adequação à natureza do trabalho no campo (BRASIL, 1996).

Conforme Munarim (2011), as escolas do campo compreendem não somente aquelas classificadas pelo Instituto Brasileiro de Geografia e Estatística (IBGE) com sede nos espaços geográficos rurais, mas também aquelas situadas em áreas urbanas que se identificam com o campo, atendendo as suas populações. Em outras palavras, “[...] a identidade da escola do campo é definida não exclusivamente pela sua situação espacial não urbana, mas prioritariamente pela cultura, relações sociais, ambientais e de trabalho dos sujeitos do campo que a frequentam”. (MUNARIM, 2011, p.12). 
Entretanto, o Movimento de Educação do Campo, no bojo de suas lutas e resistência, tem defendido uma educação no e do campo (CALDART, 2011):

[...] "no campo", porque o povo tem direito de ser educado preferentemente onde vive, isto é, sem ter que submeter-se forçosamente a longos e cansativos transportes para escolas situadas em realidades, mormente, urbanas; "do campo", porque o povo tem o direito a uma educação pensada desde o seu lugar e com a sua participação, vinculada a sua cultura e as suas necessidades humanas e sociais. Trata-se, portanto, de uma educação dos e não para os sujeitos do campo, que combine pedagogias de maneira a fazer uma educação que forme e cultive identidades, autoestima, valores, memórias, saberes, sabedoria. (MUNARIM, 2011, p.12, grifos do autor).

Considerando o exposto, busca-se, neste momento, elucidar a interface entre a educação especial e a educação do campo (grifo nosso). A importância desta interface está disposta em diversos documentos político-normativos brasileiros (BRASIL, 2002; 2008a; 2008b; 2014).

As Diretrizes Operacionais para a Educação Básica nas Escolas do Campo (BRASIL, 2002), em seu Art. $2^{\circ}$, fazem previsão para que as escolas do campo adequem seu projeto institucional às diretrizes da educação especial.

Por sua vez, a Resolução CNE/CEB n. 2/2008 estabelece, no parágrafo $5^{\circ}$ do Art. $1^{\circ}$, a necessidade dos sistemas de ensino adotarem providências para que as crianças e adolescentes com necessidades especiais, que vivem no campo, tenham acesso à educação básica, preferencialmente em escolas comuns da rede regular de ensino (BRASIL, 2008b).

Ainda, a Política Nacional de Educação Especial na Perspectiva da Educação Inclusiva (BRASIL, 2008a, grifos nossos) dispõe que:

\begin{abstract}
A interface da educação especial na educação indígena, do campo e quilombola deve assegurar que os recursos, serviços e atendimento educacional especializado estejam presentes nos projetos pedagógicos construídos com base nas diferenças socioculturais desses grupos.
\end{abstract}

Diante do dispositivo do texto da política supracitado, cabe questionar como tem se dado a observância das "diferenças socioculturais" na elaboração da interface educação especial - educação do campo no contexto político da prática, ou seja, no “chão da escola”. Em outras palavras, cumpre, na avaliação da política, verificar se a atuação da educação especial nas escolas do campo tem se atentado, quando da 
elaboração de estratégias e recursos pedagógicos, aos princípios, valores, culturas e especificidades dos alunos oriundos do campo ou se tão-somente tem reproduzido um modelo de educação especial "urbanocêntrico" nas escolas do campo.

Por fim, vale destacar o Plano Nacional de Educação (2014-2024), aprovado pela Lei n. 13.005, de 25 de junho de 2014 (BRASIL, 2014), no que tange à previsão da interface. O Plano propõe, em sua Meta 4, a universalização, para o público alvo da educação especial, na faixa etária de 4 (quatro) a 17 (dezessete) anos, o acesso à educação básica e ao atendimento educacional especializado, preferencialmente na rede regular de ensino, assegurando um sistema educacional inclusivo. Nesse sentido, prevê, como uma de suas estratégias: “[...] implantar, ao longo deste PNE, salas de recursos multifuncionais e fomentar a formação continuada de professores e professoras para o atendimento educacional especializado nas escolas urbanas, do campo, indígenas e de comunidades quilombolas". (BRASIL, 2014).

O Plano Nacional de Educação (2014-2024) reitera a tendência da política atual de educação especial com orientação inclusiva em focalizar a sua atuação para a oferta do atendimento educacional especializado em salas de recursos multifuncionais. Tendência esta que tem enfrentado críticas por pesquisadores da área (MENDES; MALHEIRO, 2012; BRUNO, 2012; NOZU, 2013). Mendes e Malheiro (2012) entendem a política de atendimento educacional especializado em salas de recursos multifuncionais como um tipo de "serviço tamanho único" que explicita uma simplificação dos serviços de apoio da educação especial e que não encontra, na literatura científica da área, sustentação em termos de efetividade. Por sua vez, Bruno (2012) tem compreendido que este "modelo único" representa uma tática geral de governamentalidade que coloca em funcionamento a lógica do mercado e a instrumentalização da educação especial.

\section{O cenário epistemológico: a produção do conhecimento acadêmico na interface}

A articulação da educação especial com a educação do campo é tema pouco explorado nas produções acadêmicas na seara da educação. Caiado e Meletti (2011) e Jesus e Anjos (2012) revelam a escassez de produções científicas referentes à interface entre educação especial e educação do campo. Da mesma forma, Marcoccia (2011, p.64) afirma que "[...] a pouca quantidade de trabalhos acerca da interface educação do campo e educação especial revela que a trajetória da temática no campo das pesquisas 
em educação no país está em fase inicial, portanto, é uma história que precisa ser construída".

Em busca realizada no Banco de Teses da Capes e na Biblioteca Digital de Teses e Dissertações sobre pesquisas acadêmicas que relacionam a articulação da educação especial com a educação do campo, foram encontradas a tese de Gonçalves (2014) e as dissertações de Marcoccia (2011) e Souza (2012).

A tese de Gonçalves (2014), intitulada Alunos com Deficiência na Educação de Jovens e Adultos em Assentamentos Paulistas: Experiências do PRONERA, defendida junto à Universidade Federal de São Carlos, sob orientação da Prof ${ }^{a}$. Dr ${ }^{a}$. Katia Regina Moreno Caiado, analisou a situação educacional da pessoa jovem e adulta com deficiência oriundas do campo, trabalhando, assim, com a interface entre a Educação Especial, Educação de Jovens e Adultos e Educação do Campo.

A dissertação de Marcoccia (2011), sob o título Escolas Públicas do Campo: Indagações sobre a Educação Especial na Perspectiva da Inclusão Educacional, vinculada à Universidade Tuiuti do Paraná e orientada pela Prof ${ }^{a}$. Dr ${ }^{\mathbf{a}}$. Maria Antônia de Souza, buscou compreender a educação especial pelo prisma da inclusão educacional vivenciada nas escolas estaduais do campo do Estado do Paraná.

Souza (2012), em sua dissertação Educação do Campo e a Escolarização de Pessoas com Deficiência: uma Análise dos Indicadores Sociais do Paraná, apresentada junto à Universidade Estadual de Londrina, com orientação da Prof ${ }^{a}$. Dr ${ }^{a}$. Sílvia Márcia Ferreira Meletti, mapeou e analisou os índices de matrícula dos alunos com deficiência que residem no campo no Estado do Paraná.

Além destas produções, Caiado (2015, p.84) registra quatro dissertações que tratam desta interface:

Projeto rural: análise das interações entre classe especial e classe regular, fora do ambiente escolar, Vale do Paraíba/SP; pesquisa desenvolvida no Programa de Pós-Graduação em Educação da Universidade Estadual do Rio de Janeiro, cujo objetivo foi acompanhar, observar, descrever, descrever e analisar as experiências no processo interativo com alunos da classe especial e com alunos da classe regular desenvolvidas em quatro encontros, na Fazenda Santa Maria, município de Taubaté, no Vale do Paraíba, em São Paulo (RICHE, 1994). Silva (2001), com a dissertação intitulada "O trabalhador com (d)eficiência física na área de assentamento rural", no Programa de Pós-Graduação em Educação da Universidade Federal da Paraíba, interessada em analisar as condições materiais e subjetivas de vida de trabalhadores com deficiência física. Em 2007, a dissertação intitulada "Adolescente com altas habilidades/superdotação de um 
assentamento rural: um estudo de caso, no Programa de PósGraduação em Psicologia da Universidade Católica Dom Bosco, apresentou pesquisa em uma escola rural na cidade de Sidrolândia, Mato Grosso do Sul, com um aluno residente num assentamento rural que se classificou em $3^{\circ}$ lugar na Olimpíada Brasileira de Matemática das Escolas Públicas (OBMP). Em 2009 surgiu a pesquisa "As políticas de formação do profissional docente em face da perspectiva inclusiva no campo: do legal às vozes dos professores, desenvolvida no Programa de Pós-Graduação em Educação da Universidade Federal do Espírito Santo, com o objetivo de analisar as políticas municipais de formação do professor para atuarem em escolas do campo com alunos da educação especial, no município de Guarapari/ES. (PONZO, 2009).

Ainda, considerando que os povos indígenas são considerados sujeitos da educação do campo, destacam-se as dissertações que tratam da interface entre a educação especial e a educação indígena, desenvolvidas junto ao Programa de PósGraduação em Educação da Universidade Federal da Grande Dourados, orientadas pela Prof ${ }^{a}$. Dra . Marilda Moares Garcia Bruno: o trabalho de Michele Aparecida, defendido em 2011, intitulado O Escolar Indígena com Deficiência Visual na Região da Grande Dourados, MS: um Estudo sobre a Efetivação do Direito à Educação; a dissertação de Luciana Lopes Coelho, apresentada em 2011, sob o título A Constituição do Sujeito Surdo na Cultura Guarani-Kaiowá: os Processos Próprios de Interação e Comunicação na Família e na Escola; a pesquisa A Criança Indígena Surda na Cultura GuaraniKaiowá: um Estudo sobre as Formas de Comunicação e Inclusão na Família e na Escola, de Juliana Maria da Silva Lima, defendida em 2013; também em 2013, o estudo de Maria do Carmo Encarnação Costa de Souza, denominado A Organização do Atendimento Educacional Especializado nas Aldeias Indígenas de Dourados/MS: um Estudo sobre as Salas de Recursos Multifuncionais; e dissertação de João Henrique da Silva, defendida em 2014, com o título Formação de Professores para o Atendimento Educacional Especializado em Escolas Indígenas.

Ademais, para ilustrar o cenário de produção do conhecimento no que tange às áreas da educação especial e da educação do campo, realizou-se busca no site do Conselho Nacional de Desenvolvimento Científico e Tecnológico (CNPq) junto ao Diretório de Grupos de Pesquisa no Brasil, mediante consulta parametrizada (BRASIL, s.d).

Ao utilizar o termo de busca educação especial para consultar os grupos de pesquisa certificados e não-atualizados, tendo como filtro a Área da Educação, foram 
registrados o total de 155 grupos em que o termo educação especial consta no Nome do Grupo, Nome da Linha de Pesquisa ou como Palavra-Chave de Linha de Pesquisa. O mesmo procedimento foi realizado com o termo educação do campo, para o qual foi apontado o total de 150 grupos de pesquisa (grifos nossos).

Em consulta em que os descritores educação especial e educação do campo foram combinados, o Diretório registrou somente dois grupos de pesquisa, ambos vinculados à Universidade Federal de São Carlos: o Grupo de Estudos e Pesquisas sobre Educação do Campo - GEPEC/HISTEDBR, que tem como líder o Prof. Dr. Luiz Bezerra Neto; e o Núcleo de Estudos e Pesquisas em Direito à Educação - Educação Especial, coordenado pela Prof ${ }^{a}$. Dra ${ }^{a}$. Katia Regina Moreno Caiado e pela Prof ${ }^{a}$. Heulália Charalo Rafante (grifos nossos).

Rabelo e Caiado (2014) destacam outros grupos de pesquisa que têm divulgado trabalhos na interface educação especial - educação do campo: a Rede de Educação Inclusiva na Amazônia Paraense, coordenada pela Prof ${ }^{a}$. Dr ${ }^{\mathrm{a}}$. Ivanilde Apoluceno de Oliveira da Universidade Estadual do Pará; e o Grupo de Estudos e Pesquisas em Educação Inclusiva, coordenado pela Prof ${ }^{a}$. Dr ${ }^{a}$. Marilda Moraes Garcia Bruno da Universidade Federal da Grande Dourados.

Ante o exposto, fica evidente, tal como já apontaram Marcoccia (2011), Caiado e Meletti (2011) e Caiado (2015), que a produção do conhecimento na interface entre a educação especial e a educação do campo ainda é escassa e está em processo de construção. Cabe, em momento oportuno, para aprofundar o campo epistemológico, mapear as temáticas e as tendências teórico-metodológicas que estão utilizadas para o desenvolvimento das pesquisas acadêmicas que tratam desta interface.

\section{Interface educação especial - educação do campo: desafios políticos e epistemológicos}

Considerando que tanto a educação especial quanto a educação do campo são historicamente marginalizadas no cenário educacional brasileiro (CAIADO; MELETTI, 2011; MAZZOTTA, 2005; CALDART, 2011), a seguir serão elucidadas aproximações entre estas duas áreas educacionais e alguns desafios para a construção da interface.

Marcoccia (2011, p.157) destaca alguns aspectos que delineiam a interface entre educação especial e educação do campo: 
1) ambas são fruto das contradições oriundas dos condicionantes históricos estruturais, a exemplo da concentração da terra e da riqueza; 2) são também fruto das lutas de organizações e movimentos sociais contra os múltiplos processos de exclusão social; 3) ambas evidenciam a luta pelo reconhecimento da vida das pessoas e das suas necessidades básicas; 4) colocam em evidência as relações socioculturais excludentes que foram construídas historicamente no Brasil; 5) as lutas e demandas desencadeadas pelos diversos sujeitos sociais têm desencadeado respostas dos governantes, que aparecem no formato de parcerias e programas com temporalidade prevista.

Por sua vez, Oliveira (2014) aponta a existência de uma relação teórica entre a educação especial com perspectiva inclusiva e a educação do campo, considerando que ambas compartilham das seguintes matrizes educacionais: autonomia, trabalho, cultura, eticidade e criticidade.

Ainda, é possível elencar outras aproximações entre educação especial e educação do campo: ambas sofrem descaso na seara das ações governamentais (CAIADO; MELETTI, 2011; CAIADO, 2015); são historicamente atingidas por práticas assistencialistas (MAZZOTTA, 2005; CALDART, 2011); tem seus públicos alvos inferiorizados, estigmatizados e estereotipados (FERNANDES; CERIOLI; CALDART, 2011; SANTOMÉ, 2013); encontram-se em situação de invisibilidade (MARCOCCIA, 2011); são vozes ausentes na seleção da cultura e do currículo escolar (SANTOMÉ, 2013).

Caiado (2015) aponta alguns desafios para definição de políticas públicas na área, tais como: a revisão da definição de urbano e rural para definir as políticas públicas; a ampliação da produção do conhecimento na área, de modo a “[...] avançar na reflexão sobre um projeto e uma prática pedagógica do campo em que pessoas com deficiência, sujeitos do campo, também se constituam sujeitos da educação do campo" (CAIADO, 2015, p.86); a ampliação de políticas públicas de financiamento da educação do campo, já que esta modalidade é marcada pelo descaso; o conhecimento da educação do campo para a organização de propostas relevantes para a interface.

Ademais, outras problematizações podem ser estabelecidas para se pensar os desafios da interface educação especial - educação do campo no contexto do "chão da escola": estariam muitos alunos oriundos do campo, matriculados em escolas urbanas, sendo identificados como "deficientes" em função de diferenças socioculturais? Estão as escolas do campo atendendo seus alunos em conformidade com as especificidades das populações do campo, no que tange aos aspectos socioculturais e educacionais 
especiais? $\mathrm{O}$ atendimento educacional especializado ofertado nas salas de recursos multifuncionais das escolas do campo tem sido realizado com base nas premissas de existência do homem do campo ou tem reproduzido um modelo de educação especial "urbanocêntrico"?

Ante estas questões, salienta-se a necessidade de que a articulação entre a educação especial e a educação do campo seja pautada em propostas pedagógicas fundamentadas no princípio da educação inclusiva (RABELO; CAIADO, 2014). Assim, a propositura de uma interface inclusiva que atenda as especificidades dos alunos público-alvo da educação especial oriundos do campo irá requerer “[...] mudanças nos processos de gestão, na formação de professores, nas metodologias educacionais, etc. com ações compartilhadas e práticas colaborativas que respondam às necessidades de todos os alunos" (SEBASTIÁN HEREDERO, 2010, p.197) (grifo nosso).

\title{
INTERFACE SPECIAL EDUCATION - RURAL EDUCATION: POLICY GUIDELINES AND KNOWLEDGE PRODUCTION IN BRAZIL
}

\begin{abstract}
This text has focus on the articulation between the Special Education and the Rural Education. Precisely, it seeks for introduce the Political and Epistemological scenarios of the interface between the two mentioned education modalities in Brazil. Therefore, the clarified ideas in this work were organized in three moments. First of all, it was selected precepts provided by the Brazilian political-normative documents related to Special Education, Rural Education and the interface between both. In the next step, this paper indicates a brief overview of the production of academic knowledge based on data provided from doctoral dissertations, master's theses and the performance of studies group of the subject. Finally, it is established approximations between the Special Education and the Rural Education and also it is beckoned for some Political and Epistemological challenges for the interface between these education modalities.
\end{abstract}

Key words: Inclusive education. Special education. Rural education.

\section{REFERÊNCIAS}

BRASIL. Ministério da Ciência, Tecnologia e Inovação. Consulta parametrizada. Brasília, DF: CNPq, s.d. Disponível em: <http://dgp.cnpq.br/dgp/faces/consulta/consulta_parametrizada.jsf >. Acesso em: 27 ago. 2015 
Decreto n. 7.611 de 17 de novembro de 2011. Dispõe sobre a educação especial, o atendimento educacional especializado e dá outras providências. Brasília, DF: Presidência da República, 2011.

Diretrizes operacionais para a educação básica nas escolas do campo. Brasília, DF: MEC/SECAD, 2002.

Ministério da Educação. Lei n. 9.394/96, de 20 de dezembro de 1996. Estabelece as Diretrizes e Bases da Educação Nacional. Brasília, DF: Senado Federal, 1996.

Lei n. 13.005, de 25 de junho de 2014. Aprova o Plano Nacional de Educação - PNE e dá outras providências. Brasília, DF: Congresso Nacional, 2014.

Política nacional de educação especial na perspectiva da educação inclusiva. Brasília, DF: MEC/SEESP, 2008a.

Resolução CNE/CEB n. 4, de 2 de outubro de 2009. Institui Diretrizes Operacionais para o Atendimento Educacional Especializado na Educação Básica, modalidade educação especial. Brasília, DF: MEC/CNE/CEB, 2009.

Resolução n. 2, de 28 de abril de 2006. Estabelece diretrizes complementares, normas e princípios para o desenvolvimento de políticas públicas de atendimento da Educação Básica do Campo. Brasília, DF: MEC/ CNE/CEB, 2008b.

BRUNO, M. M. G. Diretrizes nacionais de educação especial: convergências e divergências para sua implementação. In: CARVALHO, C. H. (Org.). Desafios da produção e da divulgação do conhecimento. Uberlândia, MG: EDUFU, 2012, p.99114. $1 \mathrm{v}$.

BUENO, J. G. S. As políticas de inclusão escolar: uma prerrogativa da educação especial? In: BUENO, J. G. S.; MENDES, G. M. L.; SANTOS, R. A. Deficiência e escolarização: novas perspectivas de análise. Araraquara: Junqueira\&Marin; Brasília, DF: CAPES, 2008. p.43-63.

CAIADO, K. R. M.; MELETTI, S. M. F. Educação especial na educação do campo: 20 anos de silêncio no GT 15. Revista Brasileira de Educação Especial, Marília, v.17, p.93-104, mai./ago. 2011.

CAIADO, K. R. M. Educação especial no campo: uma interface a ser construída. In: BAPTISTA, C. R. (Org.). Escolarização e deficiência: configurações nas políticas de inclusão escolar. São Carlos: Marquezine \& Manzini; ABPEE, 2015. p.75-89.

CALDART, R. S. Por uma educação básica do campo: traços de uma identidade em construção. In: ARROYO, M. G.; CALDART, R. S.; MOLINA, M. C. (Org.). Por uma educação do campo. 5.ed. Petrópolis: Vozes, 2011. p.147-158.

FERNANDES, B. M.; CERIOLI, P. R.; CALDART, R. S. Primeira Conferência Nacional "Por Uma Educação Básica do Campo": texto preparatório. In: ARROYO, M. G.; CAlDART, R. S.; MOLINA, M. C. (Org.). Por uma educação do campo. 5.ed. Petrópolis: Vozes, 2011. p.19-62. 
GONÇALVES, T. G. G. L. Alunos com deficiência na educação de jovens e adultos em assentamentos paulistas: experiências do PRONERA. 2014. 199 f. Tese (Doutorado em Educação Especial) - Universidade Federal de São Carlos, São Carlos, 2014.

HALL, S. A identidade cultural na pós-modernidade. 11.ed. Rio de Janeiro: DP\&A, 2011.

JESUS, D. M.; ANJOS, C. F. Tecendo interfaces entre a educação especial e a educação do campo: o cenário do Espírito Santo. In: XVI ENDIPE - Encontro Nacional de Didática e Práticas de Ensino, 2012, Campinas. Anais... Campinas: UNICAMP, 2012. p.1820-1829.

MARCOCCIA, P. C. P. Escolas públicas do campo: indagação sobre a educação especial na perspectiva da inclusão educacional. 2011. 191 f. Dissertação (Mestrado em Educação) - Universidade Tuiuti do Paraná, Curitiba, 2011.

MAZZOTTA, M. J. S. Educação especial no Brasil: história e políticas públicas. 5.ed. São Paulo: Cortez, 2005.

MENDES, E. G.; MALHEIRO, C. A. L. Sala de recursos multifuncionais: é possível um serviço "tamanho único" de atendimento educacional especializado? In: MIRANDA, T. G.; GALVÃO FILHO, T. A. (Org.). O professor e a educação inclusiva: formação, práticas e lugares. Salvador: EDUFBA, 2012. p.349-365.

MUNARIM, A. Prefácio: Educação do campo: desafios teóricos e práticos. In: MUNARIM, A. et al. Educação do campo: reflexões e perspectivas. 2.ed. Florianópolis: Insular, 2011. p.9-18.

NOZU, W. C. S. Política e gestão do atendimento educacional especializado nas salas de recursos multifuncionais de Paranaíba/MS: uma análise das práticas discursivas e não discursivas. 2013. 241 f. Dissertação (Mestrado em Educação) Universidade Federal da Grande Dourados, Dourados, 2013.

OLIVEIRA, I. A. A educação especial em escolas multisseriadas do campo: matrizes educacionais e processo de inclusão escolar. In: MENDES, E. G.; CIA, F. (Org.). Inclusão escolar e o atendimento educacional. São Carlos: Marquezine \& Manzini; ABPEE, 2014. p.125-144.

RABELO, L. C. C.; CAIADO, K. R. M.. Educação especial em escolas do campo: um estudo sobre o sistema municipal de ensino de Marabá, PA. Revista Cocar, Belém, v.8, n.15, p.63-71, jan./jul. 2014.

SANTOMÉ, F. T. As culturas negadas e silenciadas no currículo. In: SILVA, T. T. (Org.). Alienígenas na sala de aula: uma introdução aos estudos culturais em educação. 11.ed. Petrópolis: Vozes, 2013. p.155-172.

SANTOS, B. S. Renovar a teoria crítica e reinventar a emancipação social. São Paulo: Boitempo, 2007. 
SEBASTIAN HEREDERO, E. A escola inclusiva e estratégias para fazer frente a ela: as adaptações curriculares. Revista Acta Scientiarum, Maringá, v.32, n.2, p.193-208, 2010.

SOUZA, S. R. C. Educação no campo e a escolarização de pessoas com deficiência: uma análise dos indicadores sociais no Paraná. 2012. 67 f. Dissertação (Mestrado em Educação) - Universidade Estadual de Londrina, Londrina, 2012.

UNESCO. Declaração de Salamanca sobre princípios, políticas e práticas na área das necessidades educativas especiais. Salamanca, Espanha: UNESCO, 1994. 